\title{
A mathematical model for the spread of oil spills in high seas
}

\section{Bambang Hendriya Guswanto*, Kiran Nirmala Achfasarty, Ari Wardayani}

Department of Mathematics, Universitas Jenderal Soedirman, Jl. Dr. Soeparno, Karangwangkal, Purwokerto, Indonesia

*Corresponding E-mail: bambang.guswanto@unsoed.ac.id

\section{ARTICLE INFO}

\section{Article History}

Received 19 March 2021

Revised 22 March 2021

Accepted 24 March 2021

\section{Keywords}

Advection-dispersion

Oil spills

Random walks

Wind direction

Wind speed

How to cite this article: Guswanto, B. H., Achfasarty, K. N., \& Wardayani, A. (2021). A mathematical model for the spread of oil spills in high seas. Bulletin of Applied Mathematics and Mathematics Education, 1(1), 9-20.

\section{ABSTRACT}

This study aims to model the distribution pattern of oil spills in high seas with the influence of wind movements. The mathematical model is derived from the random walk process of the oil spill particles by using a probability measure on a unit circle with the help of Laplace and Fourier transform. The solution to the model is also obtained by using Laplace and the Fourier transform. Based on the analysis of the solution of the model, the oil spill tends to spread in the direction of wind movement. The speed and direction of the wind movement affect the speed and direction of the spread of the oil spill particles. The larger the speed of wind movement, the faster the oil particles movement.

\section{Introduction}

There were some researches concerning mathematical models for the spread of oil spills in high seas. Mardiah et al. (2003) studied the spread of oil spills by using a mathematical model derived from mass conservations principle to simulate the concentration of oil spills distribution and then compare the result with a standard model from Worldwide Oil Spill Modeling (WOSM). Lukijanto and Purwandani (2012) discussed the spread of oil spills probably coming in Indonesia exclusive economy zone. Salim and Sutanto (2013) investigated the mathematical model for the movement of oil spills and then analyzed it by Trajectory Gnome Analysis. Ardi (2017) discussed the spread of oil spills influenced by west and east monsoon winds by using linear regression analysis. Wibowo (2018) studied the spread and slick thickness of oil spills in Cilacap sea based on an arranged scenario. Li et al. (2018) derived the mathematical model for marine oil spills by using the Euler-Lagrange method to track the spill location and the position of particles on the edge of oil slicks.

In this paper, we study the derivation of a mathematical model for the spread of oil spills in high seas by using random walks theory involving stochastic aspects and employing a probability measure on a unit circle. In the random walks process, we consider the waiting time of the oil spill 
particles to move as a stochastic aspect considered here. By this way, we may derive various models depending on the waiting time and the characteristic of the movement direction the particles perform. This is the advantage of our way to derive the model that has not been found in previous related studies as we know so far. Here, the movement of the oil spills is only influenced by an oceanographic characteristic, namely wind velocity. We assume the wind velocity and the length of the particle jumps are constants. We then investigate the solution to the model and analyzed it. We also make an animation of the spread of the oil spill.

This paper is composed of four sections. The second section contains of the methods used in studying the mathematical model. Our results and discussion concerning the model is given in the third section. The last section concludes our study concerning the model.

\section{Method}

To derive the mathematical model, we use random walks theory and employ a measure probability on unit circle. We also apply Laplace and Fourier transforms. The movement of the oil particles is only influenced by the speed and direction of wind.

We solve the model with helps of an ordinary differential equation theory and Fourier transform. The simple animation for the oil spills spread pattern is also shown by using Macromedia Flash.

\section{Results and Discussion}

This section discusses the derivation of the mathematical model. The solution of the model and its analysis are also given in this section.

\section{Model Derivation}

The high sea is assumed as $\mathbb{R}^{2}$ plane. We consider an oil particle moving in the high sea as a particle in $\mathbb{R}^{2}$ that undergoes a sequence of random jumps. The particle movement is influenced by the waiting time and direction of the particle to jump. We suppose $\phi(t), t>0$ is the probability of the particle to jump after a waiting time $t$ and $T(x ; \omega)$ is the probability of the particle to jump from a position $x \in \mathbb{R}^{2}$ in a direction $\omega \in S^{1}$ where $S^{1}=\left\{\omega \in \mathbb{R}^{2}:|\omega|=1\right\}$. Both probabilities satisfy the equations

respectively.

$$
\int_{0}^{\infty} \phi(t) d t=1 \text { and } \int_{S^{1}} T(x ; \omega) d \omega=1,
$$

We next assume that the length of the jumps is a constant $\Delta x$. Following Othmer et al. (1998), we suppose $Q_{k}(x, t)$ stands for the conditional probability of the particle to reach a position $x$ at a time $t$ after $k$ jumps, namely

$$
Q_{k}(x, t)=\int_{0}^{t} \int_{S^{1}} \phi(t-\tau) T(x-\omega \Delta x ; \omega) Q_{k-1}(x-\omega \Delta x, \tau) d \omega d \tau .
$$

Then, the particle reaches $x$ at $t$ with the probability

$$
\begin{aligned}
Q(x, t) & =\sum_{k=0}^{\infty} Q_{k}(x, t) \\
& =Q_{0}(x, t)+\int_{0}^{t} \int_{S^{1}} \phi(t-\tau) T(x-\omega \Delta x ; \omega) Q(x-\omega \Delta x, \tau) d \omega d \tau .
\end{aligned}
$$

Since $Q_{0}(x, t)$ is Dirac Delta function, namely $Q_{0}(x, t)=\delta(x) \delta(t)$, then 


$$
Q(x, t)=\delta(x) \delta(t)+\int_{0}^{t} \int_{S^{1}} \phi(t-\tau) T(x-\omega \Delta x ; \omega) Q(x-\omega \Delta x, \tau) d \omega d \tau
$$

We then suppose $q(x, t)$ is the probability of the particle to be at $x$ at $t$ with the initial position $x=0$ and time $t=0$. It follows that

$$
q(x, t)=\int_{0}^{t} \Phi(t, \tau ; x) Q(x, \tau) d \tau
$$

where $\Phi(t, \tau ; x)$ is the probability of the particle to reach $x$ at $\tau<t$ and does not jump during the time interval $t-\tau$. We also assume that

$$
\Phi(t, \tau ; x)=\Phi(t-\tau)
$$

where

$$
\Phi(t)=\int_{t}^{\infty} \phi(r) d r=1-\int_{0}^{t} \phi(r) d r
$$

that means that the particle does not jump during the time interval $(0, t)$. Thus,

$$
\begin{aligned}
q(x, t) & =\int_{0}^{t} \Phi(t-\tau) Q(x, \tau) d \tau \\
& =\delta(x) \Phi(t)+\int_{0}^{t} \int_{0}^{\tau} \int_{S^{1}} \Phi(t-\tau) \phi(\tau-r) T(x-\omega \Delta x ; \omega) Q(x-\omega \Delta x, r) d \omega d r d \tau \\
& =\Phi(t) \delta(x)+\int_{0}^{t} \int_{S^{1}} \phi(t-\tau) T(x-\omega \Delta x ; \omega) q(x-\omega \Delta x ; \tau) d \omega d \tau .
\end{aligned}
$$

Based on the equation (1), the equation (2) can be rewritten as

$$
q(x, t)=\left(1-\int_{0}^{t} \phi(r) d r\right) \delta(x)+\int_{0}^{t} \int_{S^{1}} \phi(t-\tau) T(x-\omega \Delta x, \omega) q(x-\omega \Delta x, \tau) d \omega d \tau .
$$

By using Laplace and Fourier transform, we have $\tilde{q}(x, s)=\mathcal{L}\{q(x, t)\}(s)$

$$
\begin{aligned}
& =\mathcal{L}\left\{\left(1-\int_{0}^{t} \phi(r) d r\right) \delta(x)+\int_{0}^{t} \int_{S^{1}} \phi(t-\tau) T(x-\omega \Delta x, \omega) q(x-\omega \Delta x, \tau) d \omega d \tau\right\}(s) \\
& =\delta(x) \frac{1-\tilde{\phi}(s)}{s}+\tilde{\phi}(s) \int_{S^{1}} \tilde{q}(x-\omega \Delta x, s) T(x-\omega \Delta x, \omega) d \omega .
\end{aligned}
$$

Observe that

Then,

$$
\mathcal{F}\{\tilde{q}(x, s)\}(k)=\mathcal{F}\left\{\delta(x) \frac{1-\tilde{\phi}(s)}{s}+\tilde{\phi}(s) \int_{S^{1}} \tilde{q}(x-\omega \Delta x, s) T(x-\omega \Delta x, \omega) d \omega\right\}(k) .
$$

where

$$
\widehat{\tilde{q}}(k, s)-\frac{1}{s}=\widetilde{H}(s)(-\widehat{\widetilde{q}}(k, s)+\hat{A}(k, s)),
$$

$$
\widetilde{H}(s)=\frac{\tilde{\phi}(s)}{1-\tilde{\phi}(s)}
$$

and

$$
\mathcal{F}\left\{\int_{S^{1}} \tilde{q}(x-\omega \Delta x, s) T(x-\omega \Delta x, \omega) d \omega\right\}(k)=\hat{A}(k, s) .
$$

By the equation (3) and the inverse of Laplace and Fourier transform, we get

$$
\mathcal{L}^{-1}\left\{\hat{\tilde{q}}(k, s)-\frac{1}{s}\right\}(t)=\mathcal{L}^{-1}\{\widetilde{H}(s)(-\hat{\tilde{q}}(k, s)+\hat{A}(k, s))\}(t)
$$


or

$$
\hat{q}(k, t)-1=\int_{0}^{t} H(t-\tau)\left(-\hat{q}(k, \tau)+\mathcal{L}^{-1}\{\hat{A}(k, s)\}(k, \tau)\right) d \tau
$$

and

$$
\mathcal{F}^{-1}\{\hat{q}(k, t)-1\}(x, t)=\mathcal{F}^{-1}\left\{\int_{0}^{t} H(t-\tau)\left(-\hat{q}(k, \tau)+\mathcal{L}^{-1}\{\hat{A}\}(k, \tau)\right) d \tau\right\}(x, t)
$$

or

$$
q(x, t)-\delta(x)=\int_{0}^{t} H(t-\tau)\left(-\mathcal{F}^{-1}\{\hat{q}\}(x, \tau)+\mathcal{F}^{-1}\left\{\mathcal{L}^{-1}\{\hat{A}\}\right\}(x, \tau)\right) d \tau .
$$

Consider that

$$
\mathcal{F}^{-1}\left\{\mathcal{L}^{-1}\{\hat{A}\}\right\}(x, \tau)=\int_{S^{1}} T(x-\omega \Delta x, \omega) q(x-\omega \Delta x, \tau) d \omega .
$$

Since $q(x, 0)=\delta(x)$, then the equation (4) can be rewritten as

$$
q(x, t)-q(x, 0)=\int_{0}^{t} H(t-\tau)\left(-q(x, \tau)+\int_{S^{1}} T(x-\omega \Delta x, \omega) q(x-\omega \Delta x, \tau) d \omega\right) d \tau .
$$

If the waiting probability $\phi(t)$ is Poissonian, that is

$$
\phi(t)=\frac{e^{-t / \lambda}}{\lambda}, \lambda>0, t>0,
$$

Then the Laplace transform of $\phi(t)$ is

$$
\tilde{\phi}(s)=\mathcal{L}\{\phi(t)\}=\int_{0}^{\infty} e^{-s t}\left(\frac{e^{-t / \lambda}}{\lambda}\right) d t=\frac{1}{\lambda s+1} .
$$

Consequently,

$$
\widetilde{H}(s)=\frac{\tilde{\phi}(s)}{1-\tilde{\phi}(s)}=\frac{(1 / \lambda s+1)}{1-(1 / \lambda s+1)}=\frac{(1 / \lambda s+1)}{(\lambda s / \lambda s+1)}=\frac{1}{\lambda s}
$$

Then,

$$
H(t)=\mathcal{L}^{-1}\{\widetilde{H}(s)\}=\mathcal{L}^{-1}\left\{\frac{1}{\lambda s}\right\}=\frac{1}{\lambda} \mathcal{L}^{-1}\left\{\frac{1}{s}\right\}=\frac{1}{\lambda} .
$$

Thus, the equation (5) becomes

$$
q(x, t)-q(x, 0)=\frac{1}{\lambda} \int_{0}^{t}\left(-q(x, \tau)+\int_{S^{1}} T(x-\omega \Delta x, \omega) q(x-\omega \Delta x, \tau) d \omega\right) d \tau .
$$

If both sides of the equation (6) are differentiated with respect to $t$ then

$$
\frac{\partial}{\partial t} q(x, t)=\frac{1}{\lambda}\left(-q(x, t)+\int_{S^{1}} T(x-\omega \Delta x ; \omega) q(x-\omega \Delta x, t) d \omega\right) .
$$

We next assume that $T(x ; \omega)$ is a constant or does not depend on the position $x$ and jump direction $\omega$. It means that the particle in the random walk process moves in a homogeny medium or absence of any external force field. Since

$$
\int_{S^{1}} T(x ; \omega) d \omega=1
$$


then $T(x: \omega)=1 /\left|S^{1}\right|$ where

$$
\left|S^{1}\right|=\int_{S^{1}} d \omega=2 \pi
$$

Consequently, the equation (7) is reduced to

$$
\frac{\partial}{\partial t} q(x, t)=\frac{1}{\lambda\left|S^{1}\right|}\left(\int_{S^{1}} q(x-\omega \Delta x, t)-q(x, t) d \omega\right) .
$$

We next consider the following lemma.

Lemma 2.1 (Senba \& Suzuki, 2010). If

$$
\begin{gathered}
\int_{S^{1}} \omega_{i} d \omega=0 \\
\int_{S^{1}} \omega_{i} \omega_{j} d \omega=\delta_{i j} \frac{\left|S^{1}\right|}{2}, \quad i, j=1,2,
\end{gathered}
$$

and $f=f(x)$ is a continuously twice differentiable function then

$$
\int_{S^{1}}[f(x+\omega \Delta x)-f(x)] d \omega=\frac{1}{4}\left|S^{1}\right|(\Delta x)^{2} \Delta f(x)+o\left((\Delta x)^{2}\right)
$$

as $\Delta x \rightarrow 0$.

By using Lemma 2.1, the equation (8) is reduced to

$$
\frac{\partial}{\partial t} q(x, t)=\frac{\left(\Delta x^{2}\right)}{4 \lambda} \Delta q(x, t)+o\left((\Delta x)^{2}\right)
$$

as $\Delta x \rightarrow 0$. If $\Delta x \rightarrow 0, \lambda \rightarrow 0$, and $\frac{\left(\Delta x^{2}\right)}{4 \lambda}$ is kept finite then the equation (9) becomes

where

$$
\frac{\partial}{\partial t} q(x, t)=D \Delta q(x, t)
$$

$$
D=\frac{\left(\Delta x^{2}\right)}{4 \lambda}
$$

The equation (10) is well known as diffusion equation and a constant $D$ is called by diffusion coefficient.

We next assume $T(x ; \omega)$ is not a constant satisfying the conditions

$$
\begin{aligned}
& T(x ; \omega)-T(x ;-\omega)=F(x ; \omega), \\
& T(x ; \omega)+T(x ;-\omega)=G(x ; \omega),
\end{aligned}
$$

where $F(x ; \omega) \neq 0$ that means the random walk process is influenced by an external force field. Note that

$$
\int_{S^{1}} T(x ; \omega)=1
$$

implying

$$
\frac{1}{2} \int_{S^{1}} G(x ; \omega)=1
$$


By Taylor series expansion, we obtain

$$
\begin{aligned}
T(x-\omega \Delta x ; \omega) q(x-\omega \Delta x, t)= & T(x ;-\omega) q(x, t)-\Delta x \omega \cdot \nabla T(x ;-\omega) q(x, t) \\
& +\frac{1}{2}(\Delta x)^{2}\{-\omega \cdot \nabla\}^{2} T(x ;-\omega) q(x, t)+o\left((\Delta x)^{2}\right) .
\end{aligned}
$$

Similarly,

$$
\begin{aligned}
T(x+\omega \Delta x ; \omega) q(x+\omega \Delta x, t)= & T(x ; \omega) q(x, t)+\Delta x \omega \cdot \nabla T(x ; \omega) q(x, t) \\
& +\frac{1}{2}(\Delta x)^{2}\{\omega \cdot \nabla\}^{2} T(x ; \omega) q(x, t)+o\left((\Delta x)^{2}\right) .
\end{aligned}
$$

By the equation (11), (12), (13), and (14), we have

$$
\begin{aligned}
& T(x-\omega \Delta x ; \omega) q(x-\omega \Delta x)+T(x+\omega \Delta x ; \omega) q(x+\omega \Delta x, t) \\
& \quad=G(x ; \omega) q(x, t)-\Delta x \omega \cdot \nabla F(x ; \omega) q(x, t)+\frac{1}{2}(\Delta x)^{2}\{\omega \cdot \nabla\}^{2} G(x ; \omega) q(x, t)+o\left((\Delta x)^{2}\right) .
\end{aligned}
$$

We next consider the formula

$$
F(x ; \omega)=\frac{\Delta x}{\left|S^{1}\right|} \omega \cdot f(x),
$$

where $f(x)=\left(f_{1}(x), f_{2}(x)\right) \in \mathbb{R}^{2}$ is an external force field influencing the particle jump at position $x$. Besides, we assume that $G(x ; \omega)$ is a constant. Then

since

$$
G(x ; \omega)=\frac{2}{\left|S^{1}\right|}
$$

$$
\frac{1}{2} \int_{S^{1}} G(x ; \omega)=1
$$

By isotropic conditions

$$
\begin{gathered}
\int_{S^{1}} \omega_{i} d \omega=0, \quad i=1,2, \\
\int_{S^{1}} \omega_{i} \omega_{j} d \omega=\delta_{i j} \frac{\left|S^{1}\right|}{2}, \quad i, j=1,2,
\end{gathered}
$$

where $\omega=\left(\omega_{1}, \omega_{2}\right) \in S^{1}$, and the equation (15), (16), (17), (18), and (19), we obtain

$$
-q(x, t)+\int_{S^{1}} T(x-\omega \Delta x ; \omega) q(x-\omega \Delta x, t) d \omega=\frac{(\Delta x)^{2}}{4}(\Delta q(x, t)-\nabla \cdot f(x, \tau) q(x, t))++o\left((\Delta x)^{2}\right) .
$$

Consequently, the equation (7) is reduced to

$$
\frac{\partial}{\partial t} q(x, t)=\frac{(\Delta x)^{2}}{4 \lambda}(\Delta q(x, t)-\nabla \cdot f(x, \tau) q(x, t))+o\left((\Delta x)^{2}\right)
$$

If $\Delta x \rightarrow 0, \lambda \rightarrow 0$, and $(\Delta x)^{2} / \lambda$ is kept finite then the equation (2.20) becomes

where

$$
\frac{\partial}{\partial t} q(x, t)=D(\Delta q(x, t)-\nabla \cdot f(x, t) q(x, t))
$$

$$
D=\frac{(\Delta x)^{2}}{4 \lambda}
$$

The equation (21) is known as Fokker-Planck equation. If $f(x, t)=v$ where $v=\left(v_{1}, v_{2}\right) \in \mathbb{R}^{2}$ with $v_{i}, i=1,2$ are constants then

$$
\nabla \cdot f(x, t) q(x, t)=\nabla \cdot v q(x, t)=\nabla \cdot\left(v_{1}, v_{2}\right) q(x, t)
$$




$$
=v \cdot\left(\frac{\partial}{\partial x_{1}} q(x, t), \frac{\partial}{\partial x_{2}} q(x, t)\right)=v \cdot \nabla q(x, t) .
$$

Consequently, the equation (21) becomes

$$
\frac{\partial}{\partial t} q(x, t)=D(\Delta q(x, t)-v \cdot \nabla q(x, t)) .
$$

The equation (22) is known as advection-dispersion equation that can be used to model the concentration of oil spills $q(x, t)$ in high sea at $x$ and $t$ under the influence of wind movement with a constant velocity $v=\left(v_{1}, v_{2}\right)$.

\section{Solution}

Consider the equation

$$
\begin{gathered}
\frac{\partial}{\partial t} q(x, t)=D(\Delta q(x, t)-v \cdot \nabla q(x, t)), x \in \mathbb{R}^{2}, t>0 \\
q(x, 0)=q_{0}(x), x \in \mathbb{R}^{2} \\
q(x, t)=0, t>0,|x| \rightarrow \infty .
\end{gathered}
$$

By using Fourier transform, we get

$$
\begin{gathered}
\mathcal{F}\left[\frac{\partial}{\partial t} q(x, t)\right](k, t)=\mathcal{F}[D(\Delta q(x, t)-v \cdot \nabla q(x, t))](k, t) \\
\mathcal{F}[q(x, 0)](k, 0)=\mathcal{F}\left[q_{0}(x)\right](k)
\end{gathered}
$$

or

$$
\begin{gathered}
\frac{\partial}{\partial t} \mathcal{F}[q](k, t)=D\left(-|k|^{2}-i v \cdot k\right) \mathcal{F}[q](k, t), \quad k \in \mathbb{R}^{2}, t>0 \\
\mathcal{F}[q](k, 0)=\mathcal{F}\left[q_{0}\right](k), \quad k \in \mathbb{R}^{2} .
\end{gathered}
$$

which is solved by

$$
\mathcal{F}[q](k, t)=\mathcal{F}\left[q_{0}\right](k) e^{D\left(-|k|^{2}-i v \cdot k\right) t} .
$$

Since

or

$$
\mathcal{F}\left[\frac{1}{\sigma \sqrt{2 \pi}} e^{-\frac{|x|^{2}}{2 \sigma^{2}}}\right](k)=e^{-\frac{\sigma^{2}|k|^{2}}{2}}
$$

$$
\mathcal{F}^{-1}\left[-\frac{\sigma^{2}|k|^{2}}{2}\right](x)=\frac{1}{\sigma \sqrt{2 \pi}} e^{-\frac{|x|^{2}}{2 \sigma^{2}}},
$$

then,

$$
\begin{aligned}
\mathcal{F}^{-1}\left[e^{D\left(|k|^{2}-i v \cdot k\right) t}\right](x) & =\frac{1}{2 \pi} \int_{\mathbb{R}^{2}} e^{D\left(-|k|^{2}-i v \cdot k\right) t} e^{i k \cdot x} d k \\
& =\frac{1}{2 \sqrt{\pi D t}} e^{-\frac{|x-D v t|^{2}}{4 D t}} .
\end{aligned}
$$

It follows that

$$
q(x, t)=\mathcal{F}^{-1}[\mathcal{F}[q]](x, t)=\int_{\mathbb{R}^{2}} q_{0}(x-y) \frac{1}{2 \sqrt{\pi D t}} e^{-\frac{|y-D v t|^{2}}{4 D t}} d y .
$$

If $q_{0}(x)=c_{0} \delta(x)$ then

$$
q(x, t)=\frac{c_{0}}{2 \sqrt{\pi D t}} e^{-\frac{|x-D v t|^{2}}{4 D t}} .
$$




\section{Analysis}

By using polar coordinate, for $x=\left(x_{1}, x_{2}\right) \in \mathbb{R}^{2}$, we have

implying

$$
x_{1}=r \cos \theta, x_{2}=r \sin \theta, r>0,0 \leq \theta \leq 2 \pi \text {, }
$$

$$
q=\frac{c_{0}}{2 \sqrt{\pi D t}} e^{-\frac{\left(r \cos \theta-D v_{1} t\right)^{2}+\left(r \sin \theta-D v_{2} t\right)^{2}}{4 D t}}
$$

The maximum value of $q$ is obtained when

\section{Consequently,}

$$
\left(r \cos \theta-D v_{1} t\right)^{2}+\left(r \sin \theta-D v_{2} t\right)^{2}=0 .
$$

which implies

$$
r \cos \theta-D v_{1} t=r \sin \theta-D v_{2} t=0,
$$

It means that

$$
\theta=\tan ^{-1} \frac{v_{2}}{v_{1}}
$$

$$
\theta=\tan ^{-1} \frac{v_{2}}{v_{1}}
$$

gives a direction from the position $x=\left(x_{1}, x_{2}\right)$ on a circle with a radius $r$ such that $q$ attains the maximum value at $t>0$. Observe that the direction is the direction of the wind velocity $v=\left(v_{1}, v_{2}\right)$

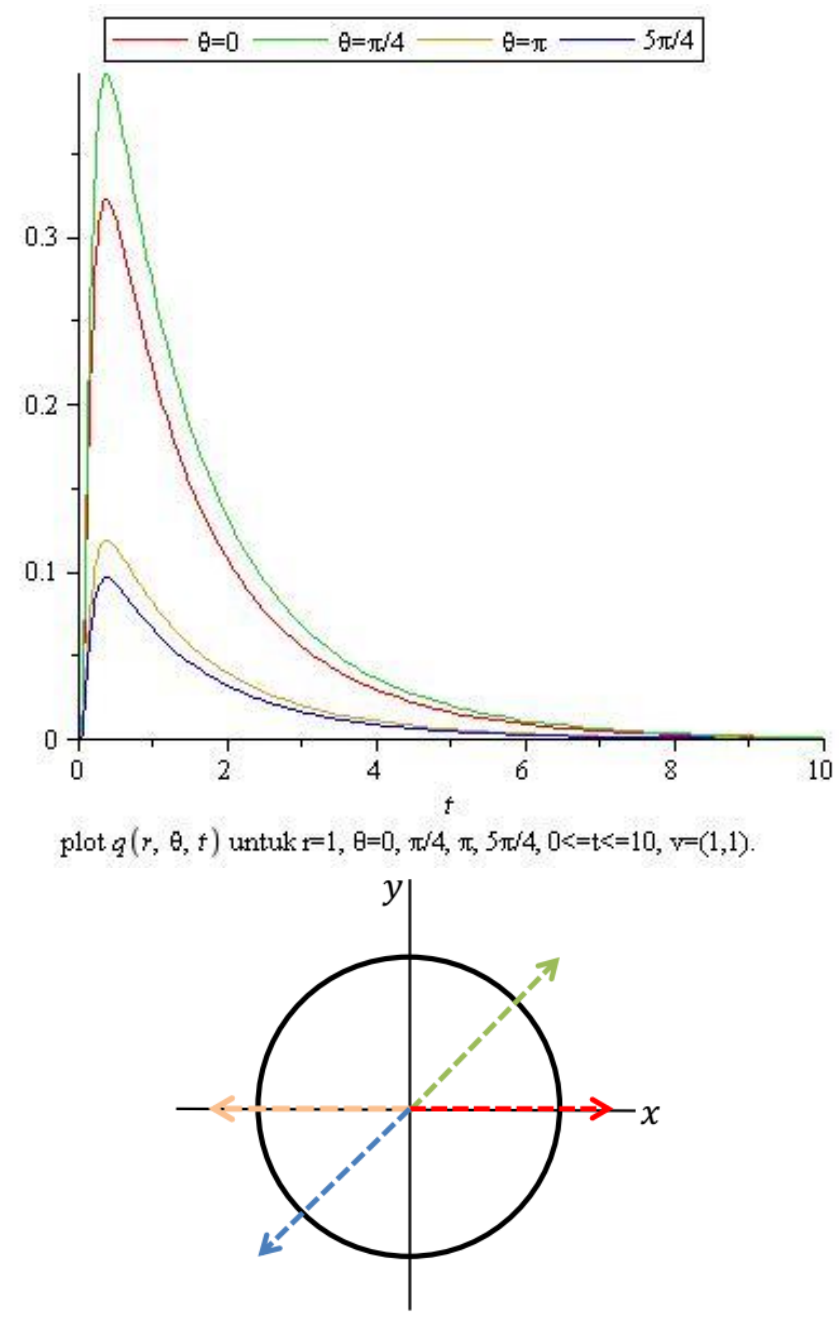

Figure 1. The graph of $q$ values at points lying on a circle with the radius $r=1$ in the movement direction $\theta=0, \pi / 4, \pi, 5 \pi / 4$ and $v=(1,1)$ along $0 \leq t \leq 10$ 
Figure 1 shows that the point lying on the circle with the movement direction $\theta=\pi / 4$ or wind velocity $v=(1,1)$ gives the largest value of $q$ along $0<t \leq 10$.

\section{Animation}

This section provides animations for the spread of the oil spill by using Macromedia Flash. Figure 2 below describes the spread of the oil spill in absence of wind movement. The spread is concentric.

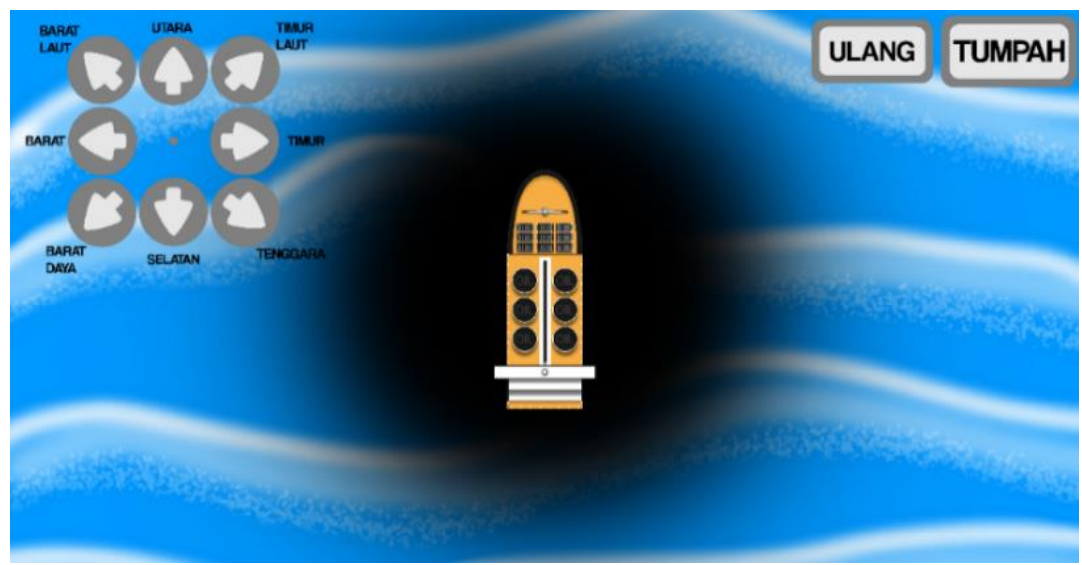

Figure 2. Screenshot of the animation when the oil spill is not influenced by wind movement

Figure 3 and 4 describe the spread of the oil spill when the wind velocities are $v=(1,1)$ and $v=(3,3)$, respectively. It seems that the oil particles tend to move in northeast direction or the direction of the wind movement. When the screenshot is taken at the same time, $t=2$ second, there is a difference between Figure 3 and 4. The oil particles in Figure 4 spread faster than that in Figure 3 since the wind movement in Figure 4 moves faster than that in Figure 3.

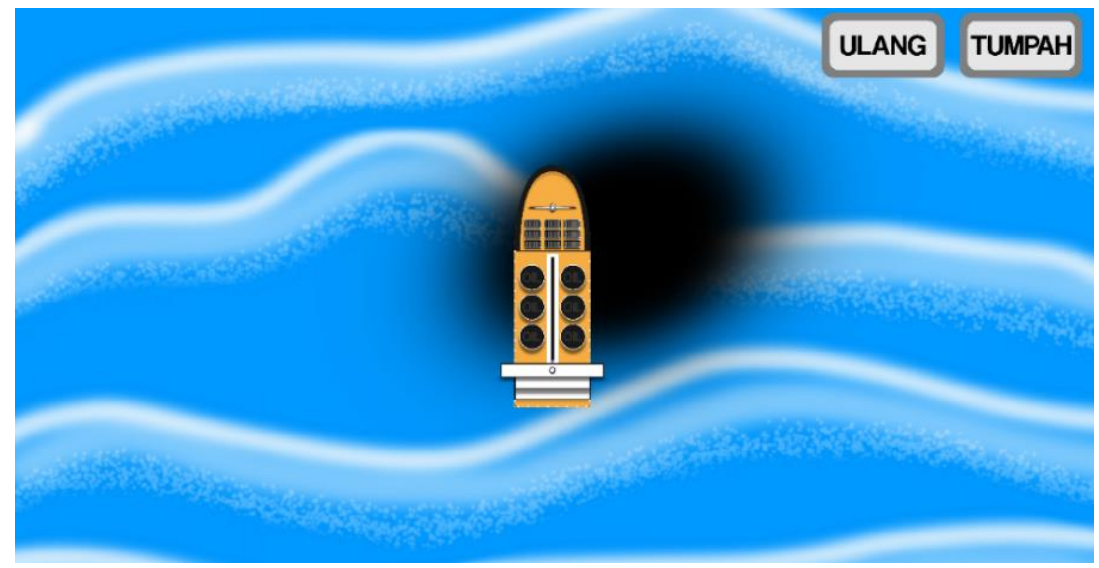

Figure 3. Screenshot of the animation when $v=(1,1)$. 


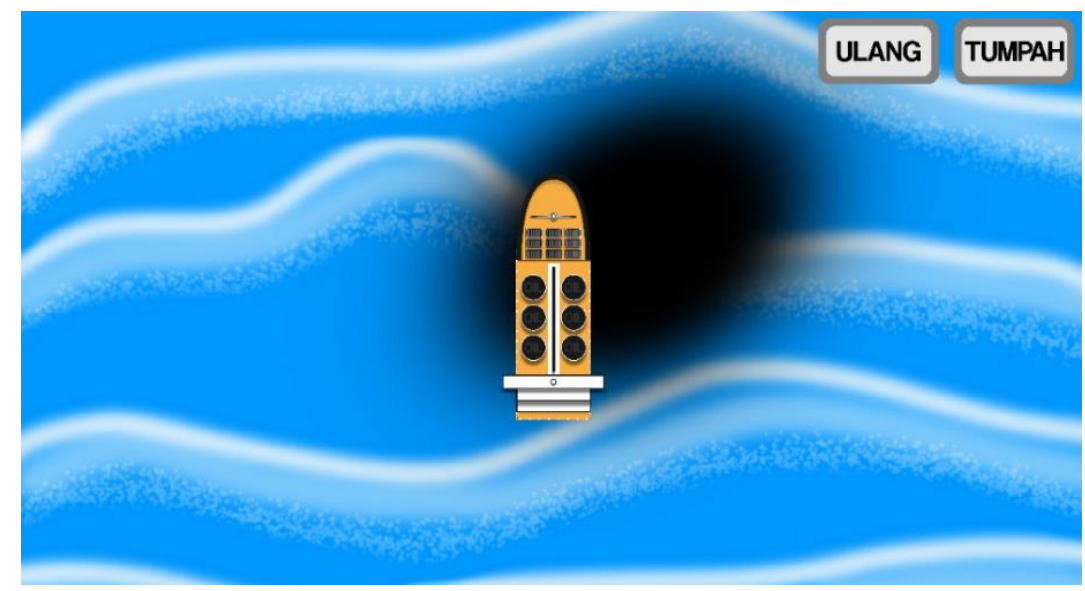

Figure 4. Screenshot of the animation when $v=(3,3)$.

Analogous to Figure 3 and 4, Figure 5 and 6 show the screenshot of the animation when the spread of the oil spill is influenced by wind velocities $v=(-1,0)$ and $v=(-3,0)$. There we can see that the oil particles tend to move in west direction or the direction of wind movement. The screenshot of the animation in Figure 5 and 6 are taken at the same time, $t=2$ second. The spread of the oil particles in Figure 5 is slower than that in Figure 6 since the wind velocities influencing the oil particles movements are also different.

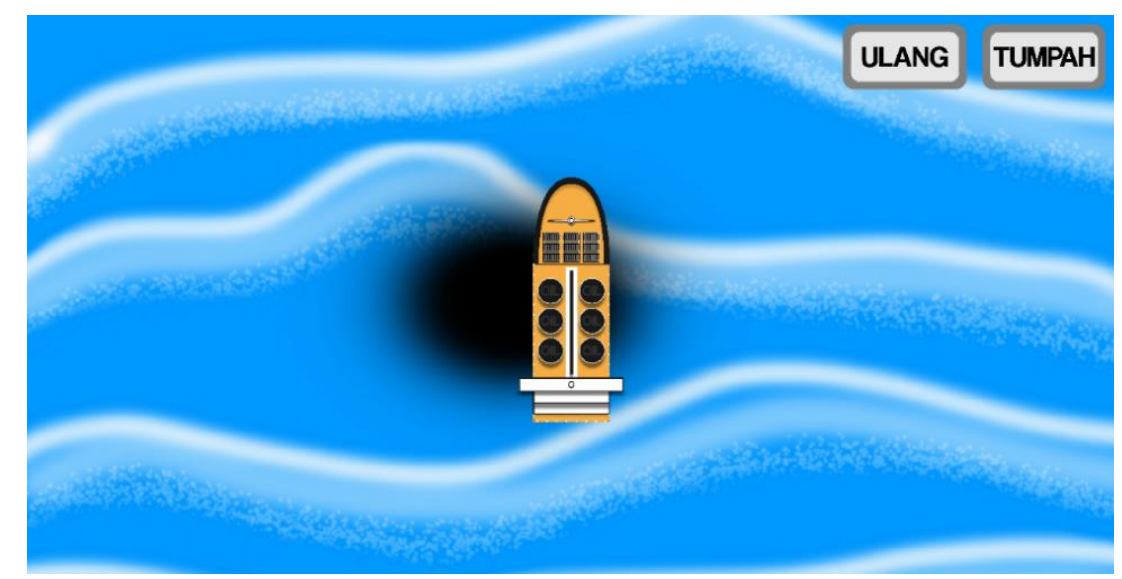

Figure 5. Screenshot of the animation when $v=(-1,0)$.

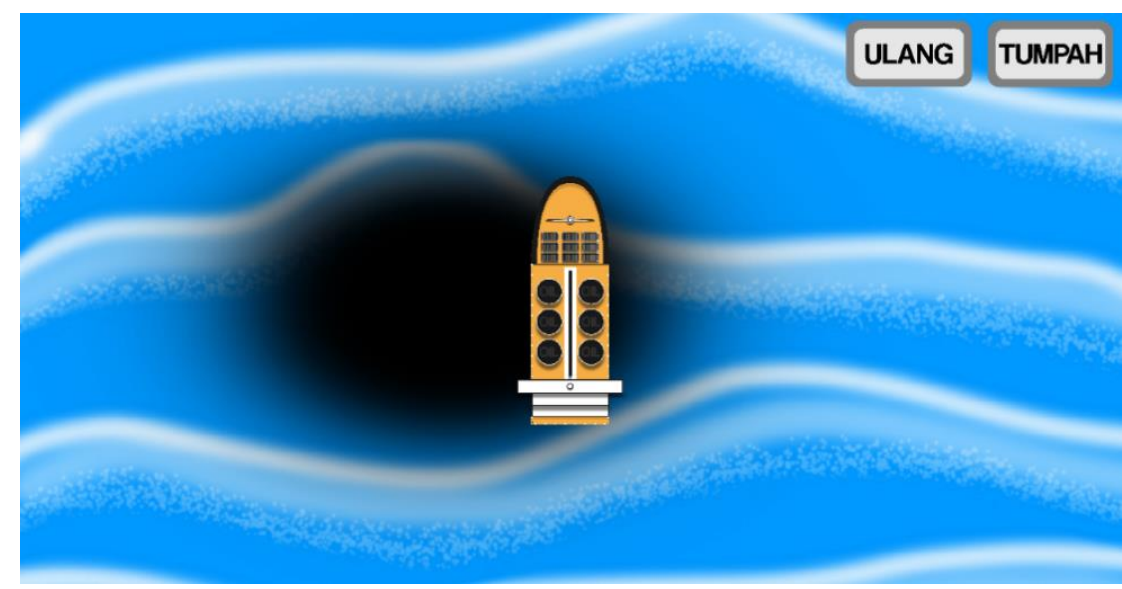

Figure 6. Screenshot of the animation when $v=(-3,0)$. 


\section{Conclusion}

The mathematical model of the spread of oil spill in high seas in presence of wind velocity is

$$
\begin{gathered}
\frac{\partial}{\partial t} q(x, t)=D(\Delta q(x, t)-v \cdot \nabla q(x, t)), \quad x \in \mathbb{R}^{2}, t>0 \\
q(x, 0)=c_{0} \delta(x), \quad x \in \mathbb{R}^{2} \\
q(x, t)=0, t>0,|x| \rightarrow \infty .
\end{gathered}
$$

where $q(x, t), v=\left(v_{1}, v_{2}\right)$, and $c_{0}$ stand for the concentration of the oil spill at position $x \in \mathbb{R}^{2}$ and $t>0$, wind velocity, and the concentration of the oil spill at $t=0$, respectively.

The solution to the model is

$$
q(x, t)=\frac{c_{0}}{2 \sqrt{\pi D t}} e^{-\frac{|x-D v t|^{2}}{4 D t}}, x \in \mathbb{R}^{2}, t>0 .
$$

Based on the analysis of the solution, we get that

$$
\theta=\tan ^{-1} \frac{v_{2}}{v_{1}}
$$

gives a direction from the position $x=\left(x_{1}, x_{2}\right)$ on a circle with a radius $r$ such that $q$ attains the maximum value at $t>0$. The direction is the direction of wind velocity $v=\left(v_{1}, v_{2}\right)$.

The animation of the spread of the oil spill shows that the speed and direction of wind movement influence the speed and direction of the spread of the oil spill. The larger the speed of wind movement, the faster the oil particles movement.

It is interesting to consider the other factors such as $\mathrm{pH}$, temperature, chemical characteristics of oil, and so on to obtain the better model via the random walks process.

\section{References}

Ardi, M. M. (2017). Pemodelan Pergerakan Pertumpahan Minyak pada Titik Rawan Kecelakaan Pelayaran (Studi Kasus: Alur Pelayaran Barat Surabaya). Surabaya: Fakultas Teknik Sipil dan Perencanaan Institut Teknologi Sepuluh Nopember.

Li, D., Tang, X., Li, Y., Wang, X., \& Zhang, H. (2018). Mathematical Modeling of Marine Oil Spills in the Luanjiakou, near the Port of Yantai. Discrete Dynamics in Nature and Society, 2018, 122.

Lukijanto, \& Purwandani, A. (2012). Pemodelan Tumpahan Minyak pada Anjungan Lepas Pantai Montana di Laut Timor. Widyariset, 15(3), 489-498.

Mardiah, Hermana, J., \& Ikhwani, H. (2003). Simulasi Sebaran Tumpahan Minyak di Perairan Dumai, PT Caltex Pacific Indonesia. Jurnal Purifikasi, 4(2), 49-54.

Othmer, H. G., Dunbar, S. R., \& Alt, W. (1998). Model of Dispersal in Biological Education. Journal of Mathematical Biology, 26, 263-298.

Salim, A., \& Sutanto, T. E. (2013). Model Pergerakan Tumpahan Minyak di Perairan Selat Sunda dengan Gnome Analysis. Jurnal Biologi, 6(2), 130-137.

Suzuki, T., \& Senba, T. (2010). Applied Analysis: Mathematical Methods in Natural Science (2nd Edition). London: Imperial College Press.

Wibowo, M. (2018). Pemodelan Sebaran Pencermaran Tumpahan Minyak di Perairan Cilacap. Jurnal Teknologi Lingkungan, 19(2), 191-202. 
BAMME Vol. 1 No. 1, April 2021, pp. 9-20

This page is intentionally left blank. 